\title{
Betaine treatment of cystathionine $\beta$-synthase- deficient homocystinuria; does it work and can it be improved?
}

This article was published in the following Dove Press journal:

Orphan Drugs: Research and Reviews

27 September 2012

Number of times this article has been viewed

\section{Kenneth N Maclean}

Department of Pediatrics, University of Colorado School of Medicine, Aurora, CO, USA
Correspondence: Kenneth N Maclean Department of Pediatrics, University of Colorado School of Medicine, Mail Stop 83I3, Aurora, CO, 80045-05II, USA

$\mathrm{Tel}+\mathrm{I} 3037243818$

$\mathrm{Fax}+\mathrm{I} 3033153838$

Email ken.maclean@ucdenver.edu

\begin{abstract}
Inactivating mutations in cystathionine $\beta$-synthase result in classical homocystinuria (HCU) and are typically accompanied by severe elevations of plasma and tissue homocysteine, methionine, S-adenosylmethionine, S-adenosylhomocysteine and significantly decreased cysteine. HCU is usually accompanied by marfanoid skeletal abnormalities, osteoporosis, ectopia lentis and/ or severe myopia, cognitive impairment, and a dramatically increased incidence of atherosclerosis and thromboembolic complications of variable presentation. If untreated, HCU is a serious lifethreatening disease. Betaine ( $N, N, N$-trimethylglycine) is a zwitterionic quaternary ammonium compound that can lower homocysteine, S-adenosylmethionine, S-adenosylhomocysteine, and increase cysteine in HCU by serving as a methyl donor for the remethylation of homocysteine in a reaction catalyzed by betaine-homocysteine S-methyltransferase. This review considers the clinical efficacy and safety of betaine treatment of HCU. Possible strategies by which the efficacy of this treatment might be improved are discussed.
\end{abstract}

Keywords: homocystinuria, homocysteine, betaine, cystathionine beta-synthase, betainehomocysteine S-methyltransferase

\section{Introduction}

In the mammalian methionine cycle, the essential amino acid methionine is transmethylated to homocysteine (Hcy), which is then either extruded into the extracellular space, transsulfurated to cystathionine and subsequently converted to cysteine or remethylated back to methionine (Figure 1). Inactivating mutations in cystathionine $\beta$-synthase (CBS) result in classical homocystinuria (HCU) and are typically accompanied by severe elevations of plasma and tissue Hcy, a range of vascular and neurological sequelae and multiple connective tissue disturbances of variable presentation. If untreated, HCU is a serious life-threatening disease. This review will consider the efficacy of betaine treatment of HCU. Possible research strategies by which the efficacy of this treatment might be improved are discussed.

\section{Betaine}

Betaine ( $N, N, N$-trimethylglycine) is a zwitterionic quaternary ammonium compound that is also known as oxyneurine, glycine-betaine, or trimethylglycine. The principal physiological functions of betaine are as an osmolyte and a methyl donor in transmethylation reactions. In this latter function, betaine supplies one-carbon units that can spare the amount of dietary methionine and choline required for nutritional purposes. In the mammalian liver and kidney, betaine serves as a methyl donor for the remethylation of Hcy in a reaction catalyzed by betaine-homocysteine S-methyltransferase (BHMT) (Figure 1) that generates methionine and dimethylglycine (DMG). ${ }^{1}$ In HCU, 


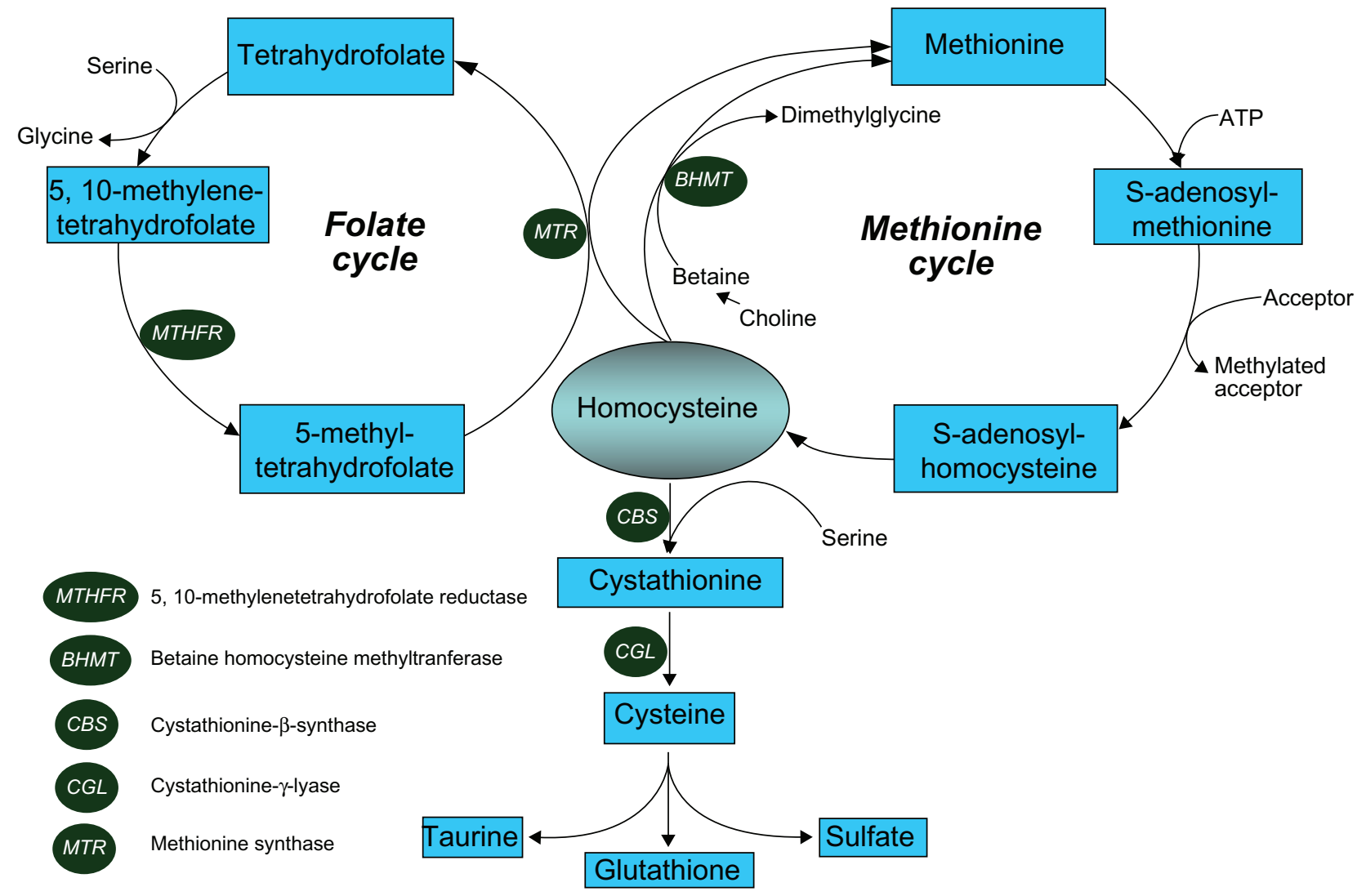

Figure I Methionine metabolism in mammals.

Note: The transsulfuration pathway and the folate and methionine cycles are shown.

betaine acts to increase the plasma and tissue concentrations of methionine and reduce the concentration of Hcy. Betaine treatment has also been observed to decrease S-adenosylmethionine (AdoMet), S-adenosylhomocysteine (AdoHcy) levels, and increase plasma DMG, methylglycine (MG), also known as sarcosine and cysteine concentrations in HCU. ${ }^{2}$

\section{Cystathionine}

\section{$\beta$-synthase-deficient HCU}

HCU is a recessively inherited disorder of the transsulfuration pathway of methionine metabolism that was first recognized in 1962., ${ }^{3,4}$ The defective enzyme in this condition was subsequently identified as CBS 2 years later. ${ }^{5}$ CBS is a hemeprotein that catalyzes the pyridoxal $5^{\prime}$-phosphate (PLP)-dependent condensation of serine and Hcy to form cystathionine, which is then converted to cysteine by another PLP-dependent enzyme, cystathionine $\gamma$-lyase (Figure 1). $\mathrm{HCU}$ is characterized biochemically by severely increased plasma and tissue Hcy, methionine, AdoMet, AdoHcy and a concomitant decrease in cysteine and frequently undetectable cystathionine. ${ }^{2,6}$ Interestingly, $\mathrm{HCU}$ does not exhibit elevated $\mathrm{DMG}^{2}$ and recent research has indicated that this is due to the fact that untreated $\mathrm{HCU}$ results in marked repression of BHMT expression. ${ }^{7}$

$\mathrm{HCU}$, if untreated, is typically accompanied by marfanoid skeletal abnormalities, osteoporosis, ectopia lentis and/or severe myopia, cognitive impairment, and a dramatically increased incidence of atherosclerosis and thromboembolic disease. ${ }^{6}$ In terms of the correlation between genotype and phenotype, there is a functional trichotomy in CBS mutations. The first class of mutations completely inactivates CBS and typically results in the severest form of the disease, often referred to as classical HCU. The second class of mutations encodes CBS protein, the deficient activity of which is increased by treatment with pyridoxine ${ }^{8}$ More recently a third functional class of CBS mutations has been observed in the C-terminal regulatory domain and result in impairment of post-translational regulation of CBS activity by AdoMet. ${ }^{2,9,10}$ To date, only a limited number of patients with these regulatory mutations have been reported, but it appears that while they incur an increased risk of thrombosis, they do not exhibit the cognitive impairment or connective tissue disturbances that are characteristic of HCU. ${ }^{2}$ There is currently little data available regarding the efficacy of betaine 
for patients with these C-terminal regulatory mutations, but it was previously noted that two patients carrying these regulatory mutations were unresponsive to therapy with either pyridoxine or betaine. $^{2}$

A landmark international survey by Mudd et al in 1985 documented the natural history of a relatively large group of HCU patients by time-to-event analyses for patients before treatment. ${ }^{11}$ In this study, vascular occlusions affecting both large and small arteries and veins were reported as the cardinal vascular signs. Of the $629 \mathrm{HCU}$ patients studied, this study reported a total of 253 vascular events in 158 patients. ${ }^{11}$ Of those vascular events, $51 \%$ involved peripheral veins (25\% of which resulted in pulmonary embolism), 32\% were cerebrovascular events, $11 \%$ affected peripheral arteries, while $4 \%$ led to myocardial infarction. Serious complications included severe hypertension due to renal infarcts, hemiparesis, cor pulmonale secondary to pulmonary artery occlusion, optic atrophy secondary to optic artery occlusion, and seizures or focal neurological signs due to cerebral thrombosis (sagittal sinus thrombosis), This analysis reported a mortality rate of $23 \%$ in pyridoxine-nonresponsive $\mathrm{HCU}$ patients and $4 \%$ in pyridoxine-responsive HCU patients by the age of 30 years. There was a $30 \%$ chance of a vascular event before the age of 20 years, which increased to $50 \%$ by the age of 30 years. This ground-breaking study effectively established baselines for subsequent studies designed to evaluate the effect of Hcylowering treatment upon clinical outcome.

\section{The evolution of Hcy-lowering treatment for $\mathrm{HCU}$ Biochemical efficacy of betaine treatment in pyridoxine-responsive $\mathrm{HCU}$}

The primary objective of HCU treatment is to reduce, and if possible normalize, the accumulation of Hcy in tissues and plasma. If this is attained during the early neonatal period and subsequently maintained, there is a good chance of preventing the development of ocular, skeletal, and thromboembolic complications and the development of normal intellectual capacity is achievable. If treatment is instigated at a later time, typically after either developmental delay or an adverse clinical event has been instrumental in initiating diagnosis, then the goal of effective biochemical control is to prevent life-threatening vascular events and to prevent further deterioration of the patient's condition. Early efforts towards this goal focused upon dietary restriction of the Hcy precursor methionine. ${ }^{12,13}$ After the discovery of a subset of HCU patients that express a defective CBS protein, and it was found that the activity of the deficient CBS protein is increased by treatment with pharmacologic amounts of pyridoxine, ${ }^{14-16}$ methionine restriction was combined with dietary supplementation with pyridoxine. As compliance with dietary methionine restriction is particularly arduous and patient response to pyridoxine is sometimes suboptimal, additional strategies to treat HCU have been sought. To date, the most effective of these has been the use of betaine. Perry et al ${ }^{17}$ pioneered the concept of dietary supplementation with a methyl donor compound to promote the BHMT catalyzed remethylation of Hcy to methionine as a treatment for HCU. This group used dietary supplementation with the betaine precursor compound choline, in combination with a methionine-restricted diet. In addition to lowering Hcy, this strategy may have had additional benefits as choline is an essential nutrient for neurodevelopment and strict adherence to a methionine-restricted diet precludes most of the richest sources of this compound. Subsequently, Komrower and Sardharwalla reported the use of betaine in combination with methionine restriction on two patients with HCU. ${ }^{18}$ In one patient, the addition of $750 \mathrm{mg} /$ day of betaine resulted in complete clearing of detectable plasma Hcy-cysteine-mixed disulfides. The other patient was treated with $6 \mathrm{~g}$ of betaine per day which resulted in the disappearance of both Hcy and the mixed disulfide with a concomitant marked increase in plasma methionine level. In 1985, Wilcken et al ${ }^{19}$ investigated the effects of betaine supplementation ( $6 \mathrm{~g}$ per day) upon methionine loading ( $4 \mathrm{~g} / \mathrm{m}^{2}$ of body area) in six treated pyridoxine-responsive patients. This group assessed the effects on plasma Hcy and methionine levels of oral methionine loads before and after adding betaine to the treatment regimen of pyridoxine and folic acid. During the 24 -hour period postmethionine challenge, all patients had higher plasma methionine and Hcy and lower cysteine compared to 17 normal control subjects. After betaine, these Hcy responses were reduced to near normal. There was a direct correlation between premethionine fasting Hcy levels and mean Hcy responses during the 24-hours postmethionine load, both before $(r=0.79)$ and after betaine $(r=0.71)$. Betaine also increased plasma cysteine levels in patients with the more severe biochemical abnormalities. Collectively, these studies indicate that betaine is a useful adjuvant therapy for optimal biochemical control in pyridoxine-responsive $\mathrm{HCU}$.

\section{Biochemical efficacy of betaine treatment in pyridoxine-nonresponsive $\mathrm{HCU}$}

For HCU patients with mutant forms of CBS that do not respond to pyridoxine therapy, methionine restriction 
remains the cornerstone of treatment. Patients diagnosed in childhood or later find the transition from a normal diet particularly difficult and compliance is frequently poor. In this scenario, betaine is an essential component of treatment with a view towards optimal biochemical control of Hcy levels. Smolin et al have previously reported the use of betaine, 6.4 and $7 \mathrm{~g} /$ day, in two pyridoxine-nonresponsive patients with HCU. ${ }^{20}$ Both patients showed significant reduction of Hcy, increased methionine, and crucially, a significant improvement in clinical symptoms. Wilcken et al reported on the effects of betaine supplementation ( $6 \mathrm{~g}$ per day) in 10 patients with pyridoxine-nonresponsive HCU in conjunction with pyridoxine ( $100 \mathrm{mg} /$ day) and folic acid ( $5 \mathrm{mg} /$ day $).{ }^{21}$ Six of these patients were also on a protein-restricted diet. All of these patients showed a substantial reduction in total free Hcy as a consequence of betaine supplementation with the average plasma level dropping from $57 \mu \mathrm{mol} / \mathrm{L}$ prior to treatment to $6 \mu \mathrm{mol} / \mathrm{L}$ during treatment. Similarly, Wilcken and Wilcken have reported that the addition of betaine treatment to standard protein restriction in 15 pyridoxine nonresponsive patients resulted in a further $75 \%$ average decline in free plasma Hcy. ${ }^{22}$ More recently, Singh et $\mathrm{al}^{23}$ reported on the biochemical benefits of betaine treatment in five patients with pyridoxine-nonresponsive HCU who could not attain optimal metabolic control by diet alone. In these patients, the addition of betaine reduced the plasma total Hcy median level by a further $47 \mu \mathrm{mol} / \mathrm{L}$. Taken together, these studies show an unequivocal benefit for betaine treatment in terms of lowering plasma Hcy levels in pyridoxine-nonresponsive HCU.

\section{Clinical efficacy of betaine treatment in $\mathrm{HCU}$ Vascular and thromboembolic complications}

Since the general introduction of betaine treatment for HCU, a number of investigators have focused their attention on the question as to whether lowering Hcy levels with this compound result in significant improvement in clinical outcome. The biggest threat to the life and health of patients with HCU is vascular or thromboembolic complications, which are predominantly peripheral and cerebrovascular. ${ }^{24-26}$

Wilcken and Wilcken ${ }^{22}$ studied a group of 15 pyridoxinenonresponsive patients who had incurred at least one vascular event previously. During the time course of this study, there were two vascular events during treatment: one fatal pulmonary embolus and one myocardial infarction. Based on previous estimates of cardiovascular events in $\mathrm{HCU}$ without treatment, ${ }^{11} 21$ vascular events would have been expected, Interestingly, there were no events during 258 patient-years of treatment in the 15 pyridoxine-nonresponsive patients $(P<0.005$ versus expected untreated $)$ receiving betaine. This study clearly demonstrated that treatment that lowers Hcy, markedly reduces cardiovascular risk in patients with HCU and that betaine therapy contributes importantly to this protective effect in pyridoxine-nonresponsive patients. Similar findings were detected in a subsequent study by Walter et al. ${ }^{27}$

In 2001, a multicenter observational study ${ }^{28}$ assessed the effectiveness of long-term Hcy-lowering treatment in reducing vascular risk in $158 \mathrm{HCU}$ patients. Vascular outcomes were analyzed and the effectiveness of treatment in reducing vascular risk was evaluated by comparison of actual to predicted number of vascular events. The 158 patients represented 2822 patient-years of treatment, with an average of 17.9 years per patient. Plasma Hcy levels were markedly reduced from pretreatment levels, but usually remained moderately elevated. A total of 17 vascular events were observed compared to a predicted 112 vascular events which would have been expected without treatment, for a relative risk of 0.09 (95\% confidence interval [CI]: $0.036-0.228 ; P<0.0001)$. In this study, patient-years of treatment were calculated separately for pyridoxineresponders and -nonresponders. Recent work has introduced an element of caution in the interpretation of this study and others like it, because of a possible ascertainment bias due to under detection of pyridoxine-responsive HCU. ${ }^{29}$ Whilst it is true that the use of multiple treatments used simultaneously makes it impossible to unequivocally delineate the individual contribution of betaine treatment to clinical outcome in $\mathrm{HCU}$, the demonstrated ability of this compound to assist in effective biochemical control strongly indicates that it exerts significant clinical benefit in this condition.

\section{Cognitive impairment}

Cognitive impairment remains the most common abnormality of the central nervous system in HCU and is frequently instrumental in the initial diagnosis, typically presenting as developmental delay in the first or second year of life. ${ }^{11}$ There is considerable variation in the presentation of cognitive impairment in HCU. A previous assessment of 629 patients by Mudd et $\mathrm{al}^{11}$ observed a relatively wide range of IQ among patients with HCU (10 to 138 with a median of 64). Pyridoxine-responsive patients had significantly higher IQs $(\mathrm{N}=107$, mean IQ $=79$ ) compared to pyridoxine-nonresponsive patients $(\mathrm{n}=115$; mean $\mathrm{IQ}=57 ; P<0.0001)$. Similar levels 
of variance in intellectual capacity were subsequently reported in two independent studies. ${ }^{30,31}$

There is currently a paucity of studies that investigate the effects of treatment upon cognitive impairment in $\mathrm{HCU}$ and to date, none that address the effects of betaine specifically. Yap et $\mathrm{al}^{32}$ investigated the cognitive capabilities of 23 pyridoxine-nonresponsive HCU patients compared to age-matched sibling controls. Of the 23 individuals, 19 were diagnosed through newborn screening with early treatment, two were late-detected and two were untreated at the time of assessment. Thirteen of the newborn-screened group, who were compliant with treatment, had no detectable cognitive impairment, while the remaining six, who had poor compliance, developed complications. The newbornscreened, good-compliance group $(n=13)$ had mean full-scale IQ (FIQ) of 105.8 (range 84-120), while the poorly compliant group $(n=6)$ had a mean FIQ of 80.8 (range $40-103)$. The control group $(n=10)$ had a mean FIQ of 102 (range 76-116). In this study, good control was defined as plasma-free Hcy median $<11 \mu \mathrm{mol} / \mathrm{L}$ and was attained solely by methionine restriction. Many patients struggle to achieve this level of control by diet alone and in this context; it is highly likely that the use of betaine in addition to methionine restriction, would almost certainly increase the number of patients able to avoid cognitive impairment as a consequence of HCU. ${ }^{32}$

\section{Ocular complications}

Untreated HCU is frequently associated with ectopia lentis (dislocation of the optic lens) and myopia. Previous work by Mudd et $\mathrm{al}^{11}$ found that by the age of 10 years, $70 \%$ of all untreated HCU patients had dislocated lenses. Subsequently, evidence has accrued indicating that early treatment delays or prevents ectopia lentis. ${ }^{27,33}$ The positive effects of optimal biochemical control upon ocular complications in HCU have recently been demonstrated. ${ }^{34}$ These investigators compared clinical outcome between 14 late-diagnosed HCU patients with lens subluxation or dislocation at diagnosis and a further 15 patients who were detected in the newborn period and remained well controlled. Of the poorly controlled patients, only $28.6 \%$ of eyes had 20/40 vision or better and all had steadily progressive myopic astigmatism and lens subluxation. Six patients who became poorly controlled in their teens or early twenties showed significant progression of their myopia, and three developed phacodonesis or lens subluxation. All of the well-controlled patients had no evidence of lens subluxation and had 20/20 vision bilaterally. The difference in visual acuity between late-diagnosed patients and the control group was highly significant $(P=0.0002)$. The differences in refractive errors between the groups were also highly significant $(P=0.0001)$. Collectively these results present a strong case for a causative relationship between poor biochemical control and the risk of ocular complications in HCU.

\section{Skeletal abnormalities}

By the age of 15 years, approximately $50 \%$ of HCU patients have radiological evidence of osteoporosis. ${ }^{24}$ Although no definitive study has been performed, all the available data indicates that betaine therapy is unable to completely prevent osteoporosis in HCU. In a small study of five patients with pyridoxine-nonresponsive $\mathrm{HCU}$, Gahl et al found that despite significant reduction in plasma Hcy levels in all patients, there was no discernible amelioration of their osteoporosis. ${ }^{35}$ A possible explanation for the failure of betaine to improve osteoporosis in HCU is discussed below.

\section{Complications of betaine therapy}

Current data indicate that betaine is a relatively safe treatment. In a previous study, with a total of 825 patient-years of betaine treatment, and periods of betaine treatment up to 17 years there were no reports of significant side effects. ${ }^{28}$ Despite this favorable outcome, the use of betaine is not without risk. The primary concern with betaine treatment is the avoidance of toxic levels of methionine $(>1000 \mu \mathrm{mol} / \mathrm{L})$ formed from the remethylation of Hcy. However, evidence from patients with methionine adenosyltransferase (MAT) I/III deficiency, which incurs severely elevated methionine without any obvious adverse effects, indicates that high levels of methionine are generally tolerable. ${ }^{36-38}$ However, cerebral edema has been reported in two HCU patients exhibiting extreme hypermethioninemia induced by betaine therapy. ${ }^{39,40}$ In both cases, discontinuation of betaine resulted in reduced methionine levels and subsequent resolution of neurological symptoms and magnetic resonance imaging abnormalities. The risk of cerebral edema in betaine treatment of severely elevated Hcy is not limited to HCU and has previously been reported in a patient with MAT I/III deficiency. ${ }^{41}$

\section{Optimal dosage and timing of betaine treatment in $\mathrm{HCU}$}

Despite widespread usage, there is currently little consensus on optimal betaine dosage and frequency of administration in human subjects with HCU. The average decrease in plasma Hcy concentration is reported to be between $74 \%$ and $92 \%$ following doses of 6-20 $\mathrm{g}^{\text {day }^{-1}}$ of betaine. ${ }^{42,43}$ However, some studies have found no clinical benefit using $6 \mathrm{~g} \mathrm{day}^{-1}$ of betaine. ${ }^{44}$ 
A number of limited trials have been performed to investigate these aspects of betaine therapy, but these have typically been limited by relatively short study durations and/or the use of normal volunteers rather than HCU patients who are likely to have different responses to the application of betaine. ${ }^{45-47}$ Some investigators have tried to model the effects of HCU for studying betaine dosing by using a methionine-loading strategy but again, the time course of this kind of analysis is not suitable for detecting possible metabolic adaption induced in long-term betaine therapy. ${ }^{48}$ In those studies that have used individuals with $\mathrm{HCU}$, the data has been complicated by the need to continue a methionine-restricted diet which, given its efficacy in lowering total Hcy (tHcy), is highly likely to mask any possible diminution in the ability of betaine to lower tHcy over time. ${ }^{49,50}$ One previous study investigated the pharmacokinetics (PK) and pharmacodynamic (PD) characteristics of betaine in six patients (aged 6-17 years) with pyridoxinenonresponsive HCU. ${ }^{48}$ Prior to commencement of the study, betaine treatment was stopped but a low-methionine diet was maintained. Betaine was then given as a single oral dose of $100 \mathrm{mg} \mathrm{kg}^{-1}$ and plasma betaine and total Hcy concentrations were measured by high-pressure liquid chromatography at frequent intervals over 24 hours. Individual plasma betaine concentration-time data were fitted by an optimal PK model, and individual concentration-time-effect data were analyzed by an indirect response PD model. Both models were then linked in an algorithm to simulate the effects of betaine dose and dosage interval on plasma Hcy concentrations. This was then applied to determine the optimal regimen of betaine to control plasma total Hcy in the HCU patients. Betaine PK was described by both mono- and biexponential disposition functions with first-order absorption and a lag time. The correlation coefficient between betaine oral clearance and body weight was 0.6 . Mean betaine clearance was higher in males than in females $(P=0.03)$. PK-PD simulation indicated minimal benefit from exceeding a twice-daily dosing schedule and a $150 \mathrm{mg} \mathrm{kg}^{-1}$ day $^{-1}$ dosage for betaine. ${ }^{49}$

While this latter study is probably the best published to date regarding the optimization of the use of betaine in $\mathrm{HCU}$, it does come with a number of limitations. Firstly, ethical considerations preclude the study of betaine in human subjects with $\mathrm{HCU}$ in the absence of the methionine-restricted diet. Secondly, betaine treatment is typically for life and the duration of the study at 24 hours was therefore unsuited to detect possible changes in the PK and PD of chronic longterm betaine treatment.

\section{Can the efficacy of betaine treatment in HCU be improved?}

Current knowledge indicates that betaine is essentially an adjunctive therapy that cannot effectively substitute for methionine restriction. ${ }^{51-53}$ Although current therapy is effective, adherence to the methionine-restricted diet is difficult and compliance is often poor especially with children who are diagnosed after experiencing a normal diet. As discussed above, betaine is regarded as a safe treatment for HCU, but its use is not without risk indicating that there is a need not to overdose HCU patients with betaine. Additionally, due to the relative rarity of $\mathrm{HCU}$, the associated costs of manufacturing betaine to the required pharmacological grade are high. If the efficacy of betaine treatment could be increased, it is conceivable that costs could be reduced and strict adherence to the methionine-restricted diet could be relaxed thus constituting a significant improvement in quality of life for individuals with HCU. A major impediment to achieving this goal is the fact that prolonged experimentation on the PK, dosing, and frequency of long-term betaine treatment, in isolation from a methionine-restricted diet, is precluded by ethical considerations regarding patient risk. Consequently, there is a need to examine the efficacy of betaine in isolation from methionine restriction in an animal model of HCU.

\section{Investigating betaine treatment using transgenic and knockout mouse models of $\mathrm{HCU}$}

\section{Cbs null mouse model of $\mathrm{HCU}$}

To date, the majority of research on HCU has been performed using a CBS knockout mouse model..$^{54}$ These Cbs (-/-) animals suffer from pronounced liver injury and typically die within 2-3 weeks of birth. This neonatal semi-lethality is not mirrored in human patients and restricts the utility of the model. Recently it has been shown that betaine treatment improved the survival of $\mathrm{Cbs}(-/-)$ mice and restored fertility to female $C b s(-/-)$ mice, but without significantly lowering Hcy. ${ }^{54}$ Surviving $C b s(-/-)$ mice failed to show any alteration in coagulation parameters compared to wild-type controls and exhibited severe liver injury, steatosis, and fibrosis that were not significantly improved by betaine treatment. The failure of betaine treatment to lower Hcy in Cbs null mice is most likely due to the influence of severe liver injury upon hepatic BHMT expression. ${ }^{55}$ The fact that betaine treatment significantly improved survival in $C b s$ null mice without significantly lowering tHcy indicates that this compound may 
exert significant protective effects in HCU independent of its role as a substrate for BHMT.

\section{The $\mathrm{HO}$ transgenic mouse model of $\mathrm{HCU}$}

To date, the only animal model of HCU that has been demonstrated to accurately recapitulate the biochemical response to betaine that is typically observed in human subjects with $\mathrm{HCU}$, is a transgenic model in which the mouse Cbs gene is inactivated and that exhibits very low-level expression of the human $C B S$ gene under the control of the human $C B S$ promoter. This mouse model, designated "human only" (HO), exhibits severe elevations in both plasma and tissue levels of Hcy, methionine, AdoMet, and AdoHcy and a concomitant decrease in plasma and hepatic levels of cysteine. ${ }^{56}$ Betaine treatment of HO mice resulted in a highly significant lowering of average tHcy levels from 257 (standard deviation $[\mathrm{SD}]=65)$ to $50 \mu \mathrm{M}(\mathrm{SD}=16.1 ; P<0.001)($ Figure $2 \mathrm{~A})$.
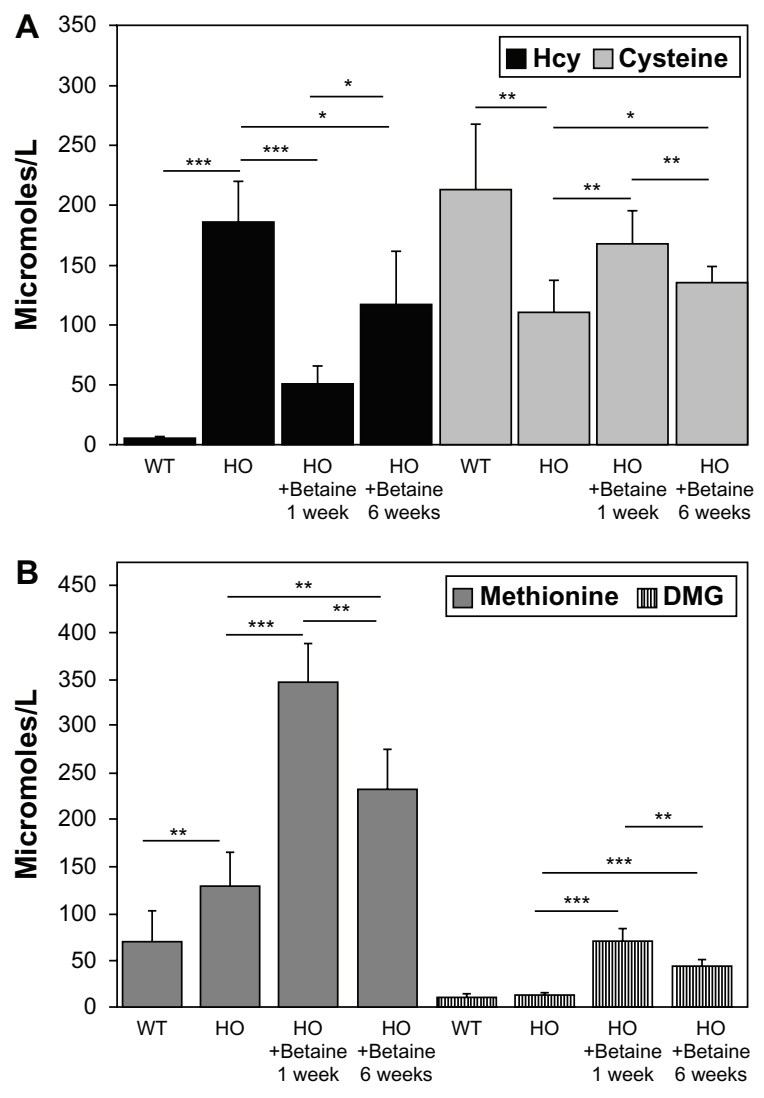

Figure 2 The ability of betaine treatment to decrease plasma thcy levels in $\mathrm{HO}$ $\mathrm{HCU}$ mice diminishes with time. Plasma levels (A) of tHcy and total cysteine and (B) methionine and DMG in WT mice, untreated $\mathrm{HO}$ mice and $\mathrm{HO}$ mice on I and 6 weeks of betaine treatment.

Notes: Values shown represent the mean and SD derived from eight animals. In this figure and all subsequent graphs presented here *, **, and *** denote $P$ values of $<0.05,0.01$, and 0.001 , respectively.

Abbreviations: $\mathrm{HCU}$, classical homocystinuria; $\mathrm{HO}$, human only; SD, standard deviation; tHcy, total homocysteine; WT, wild-type.
Similarly, there was a 4-, 4.5-, 5.6-, and 4.7 -fold increase in plasma methionine, DMG, MG, and cysteine respectively $(P<0.0001$ for all four metabolites) (Figure 2A and B). Lowering plasma tHcy by betaine treatment also resulted in a $40 \%$ decrease in plasma AdoMet $(P=0.0039)$ and a fivefold decrease in AdoHcy levels $(P<0.0001)$. Collectively, these data indicated that the $\mathrm{HO}$ mouse recapitulates the biochemical response of human subjects with HCU to betaine treatment and thus constitutes a suitable model for investigating ways to optimize the therapeutic effects of this treatment in HCU.

In addition to modeling the human HCU response at the biochemical level, tail bleeding determinations indicated that $\mathrm{HO}$ mice clot threefold faster than wild-type controls and are in a hypercoagulative state. ${ }^{55}$ Betaine treatment in the absence of dietary methionine restriction significantly decreased plasma tHcy levels $(P<0.0001)$ and concomitantly increased the clotting time in the $\mathrm{HO}$ mice $(P=0.0005) .{ }^{56}$ Subsequent work has found that $\mathrm{HO} \mathrm{HCU}$ mice exhibit a highly significant induction of the pro-inflammatory cytokines interleukin 1a (IL-1a), IL-1b, and tumor necrosis factor- $\alpha$ (TNF- $\alpha$ ). ${ }^{57}$ Similar, constitutive inductions of multiple proinflammatory cytokines (IL-1 $\alpha$, IL-6, TNF- $\alpha$, IL-17, and IL-12 [p70]) and chemotactic chemokines (fractalkine, macrophage inflammatory protein [MIP]-1 $\alpha$ and MIP-1 $\beta$ ) were observed in untreated/poorly compliant human subjects with HCU. ${ }^{57}$ In the human subjects, standard methionine-restriction and betaine treatment was associated with either normalization of all of the proinflammatory cytokines and chemokines investigated with the exception of TNF- $\alpha$, which was reduced, but remained significantly elevated compared to the normal controls. In the HO HCU mice, betaine treatment alone was sufficient to normalize all of the observed proinflammatory inflammatory cytokine expression with the exception of TNF- $\alpha$, which, while significantly reduced, remained elevated compared to wild-type control mice.

TNF- $\alpha$ has been associated with promoting osteoporosis by activating osteoclast mediated bone resorption. ${ }^{58}$ This latter possibility provides a possible explanation for the fact that osteoporosis is absent from children with Marfan syndrome but is a common feature in children with HCU. In this context, it is interesting to note that reduced bone density has been found in the HO mice (Maclean, unpublished data, 2012) and in another mouse model of HCU. ${ }^{59}$ Although no definitive study has ever been carried out, anecdotal evidence suggests that HCU-induced osteoporosis is not completely corrected by existing treatments. ${ }^{24}$ These findings suggest that patients that continue to experience reduced bone density while 
receiving conventional therapy for $\mathrm{HCU}$ might benefit from adjuvant anti-inflammatory therapy.

Apolipoprotein apoA-I is synthesized in the liver and contributes to much of the cardioprotective effects of highdensity lipoprotein. Additionally, apoA-I exerts significant neuroprotective effects that act to preserve cognition. A recent investigation of apoA-I expression in the presence and absence of betaine, in the HO mouse and betaine/ methionine restriction in human subjects with this disorder reported that plasma levels of apoA-I were significantly diminished in both untreated/poorly compliant mice and humans with HCU. ${ }^{59}$ Betaine and methionine restriction normalized plasma levels of this apolipoprotein in humans with HCU. Interestingly, betaine treatment in the absence of methionine restriction was sufficient to normalize plasma levels of apoA-1 in HO mice. Collectively this study produced data consistent with a plausible role for decreased expression of apoA-I as a contributory factor for both cardiovascular disease and cognitive impairment in HCU and that lowering Hcy with betaine may exert its protective effects at least in part by normalizing expression of this apolipoprotein. ${ }^{60}$ Previous work has shown that apoA-IV can mimic a number of the antiatherogenic functions of apoA-I. ${ }^{61,62}$ This study also indicated that apoA-IV expression is also significantly decreased in humans with HCU but that this effect is not significantly ameliorated by conventional treatment to lower tHcy and there remains significant scope for the improvement of therapy in HCU. ${ }^{60}$

\section{Possible metabolic adaption to long-term betaine treatment in $\mathrm{HCU}$}

A recent investigation of the effects of long-term betaine treatment in the absence of methionine-restriction in $\mathrm{HO}$ HCU mice revealed that the ability of betaine treatment to lower Hcy is significantly diminished over time. ${ }^{7}$ One week of betaine treatment significantly lowered the observed mean plasma tHcy level compared to the untreated HO HCU mice (50.14 $\mu \mathrm{M} \pm 16.4$ versus $186.1 \mu \mathrm{M} \pm 32.3 ; P<0.0001)$. In a 6-week betaine treatment group, there was an approximate doubling in plasma tHcy compared to the 1-week treatment group $(117 \mu \mathrm{M} \pm 45.1$ versus $50.14 \mu \mathrm{M} \pm 16.4 ; P=0.0015){ }^{7}$ The observed increase in plasma Hcy during prolonged betaine treatment was accompanied by a significant increase in the plasma levels of TNF- $\alpha$ and IL- $1 \beta$ and a reversion to a hypercoagulative phenotype. The findings of this analysis are consistent with a relatively sharp threshold effect between severely elevated plasma tHcy and thrombotic risk in HCU. Plasma metabolite analysis indicated that this effect was due, at least in part, to decreased BHMT-mediated remethylation of Hcy. These findings illustrate the importance of monitoring plasma methionine and DMG levels in addition to tHcy during routine assessments of patients with HCU. If a metabolic adaption similar to that observed in the $\mathrm{HO}$ mice were to occur in humans, it is likely that the physician might simply assume that the patient was not taking their betaine as prescribed, but this study indicates that it is possible that such patients might be exhibiting a diminished capacity to remethylate Hcy via BHMT rather than being less compliant.

\section{Optimization of betaine treatment will require greater understanding of the regulation of BHMT and the methionine cycle in $\mathrm{HCU}$}

Although much is known about the regulation of the methionine and folate cycles in normal mammals, recent work has indicated that diseases such as $\mathrm{HCU}$ might act to alter those processes and there is a case for specifically reevaluating this regulation in an animal model of HCU. For example, Western blotting analysis has revealed that BHMT protein levels are significantly repressed in untreated HCU HO mice, but are significantly induced in the presence of betaine treatment. ${ }^{7}$ The aforementioned reduction in the ability of betaine to lower plasma tHcy levels during long-term therapy with betaine poses the question as to how this metabolic adaption arises? Despite serving a fundamental metabolic role in cysteine synthesis, CBS is not ubiquitously expressed in all tissues and in the absence of transsulfuration, the methionine cycle is essentially regarded as a closed loop. ${ }^{63}$ Therefore, tissues that lack transsulfuration will require mechanism $/ \mathrm{s}$ for dealing with excess methionine. It is theoretically possible that intracellular levels of both Hcy and methionine could be decreased by the transamination of methionine but previous work has shown that this is not a significant mechanism in HCU. ${ }^{64}$ Methionine and Hcy can be extruded into the extracellular space and ultimately excreted in the urine while relatively high levels of AdoHcy result in its excretion in the urine as a keto derivative. ${ }^{65}$ Additionally, AdoMet can be converted by glycine $N$-methyltransferase to $\mathrm{MG}$ which can also be excreted in the urine. The possible effects of HCU upon the regulation of these metabolic mechanisms in the presence and absence of betaine treatment are presently unknown but clearly merit further investigation.

The observation that there are significantly higher levels of BHMT protein in the $\mathrm{HO}$ mouse undergoing long-term 

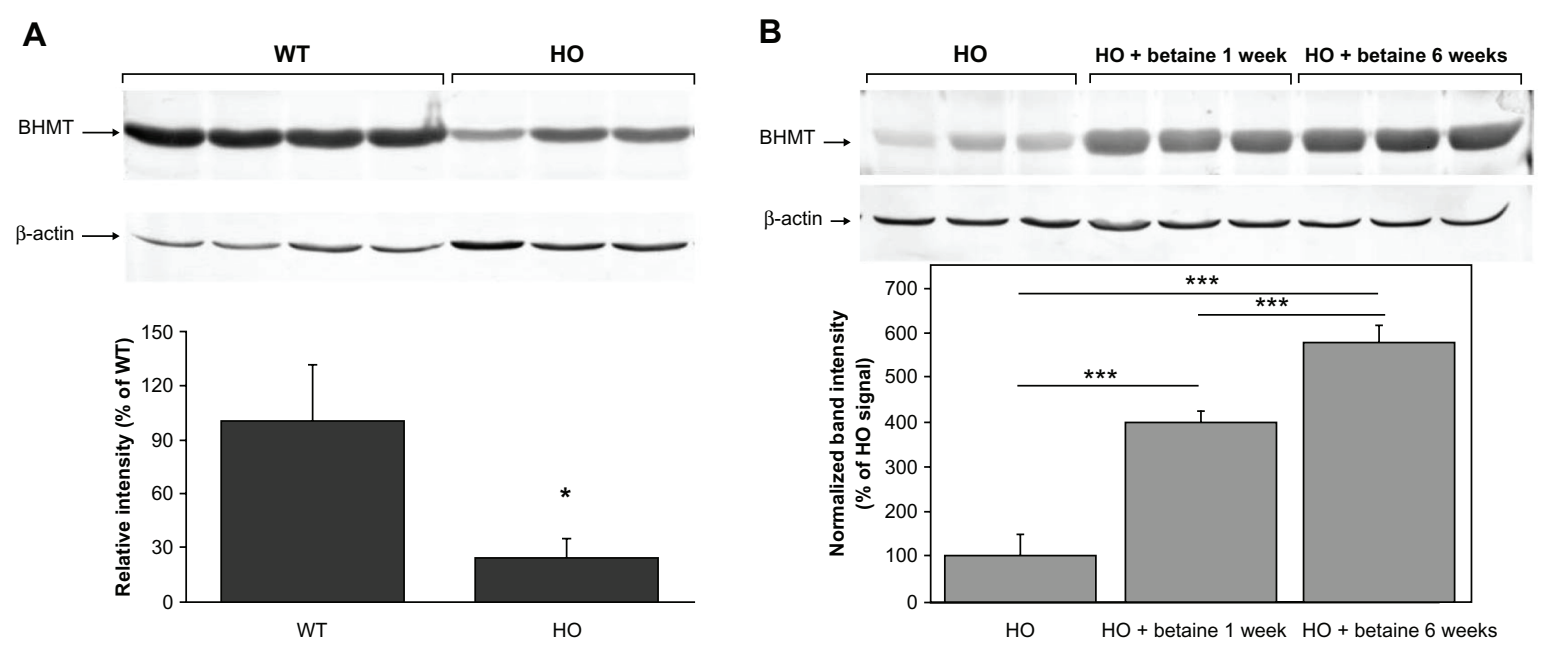

Figure 3 (A) BHMT protein levels are reduced in HO HCU mouse liver. Western blotting analysis of hepatic BHMT expression levels in WT and HO HCU mice. (B) BHMT protein levels are induced by betaine treatment in $\mathrm{HO} \mathrm{HCU}$ mouse livers.

Notes: Western blotting analysis of hepatic BHMT expression levels in HO HCU mice in the presence and absence of one or 6 weeks of betaine treatment. The relative intensities of protein bands were quantified using Quantity One software (version 4.6.5; Bio Rad). Signal intensity from BHMT bands was calculated relative to $\beta$-actin signal intensity. The blots shown are representative of two independent experiments.

Abbreviations: BHMT, betaine-Hcy S-methyltransferase; HCU, classical homocystinuria; HO, human only; SD, standard deviation; tHcy, total homocysteine; WT, wild-type.

betaine treatment where BHMT-mediated remethylation of Hcy is diminished, raises the possibility that the BHMT protein is impaired in its function in HCU (Figure 3). Previous work has indicated that DMG or AdoMet can serve as inhibitors of BHMT function, ${ }^{66}$ but this seems unlikely as the plasma levels of these metabolites are also diminished in the long-term treatment group. One possible mechanism for the diminution of BHMT enzyme activity over time is oxidative stress. Research by Miller and colleagues has reported that BHMT is prone to oxidative inactivation. ${ }^{67}$ Subsequent research has shown that purified BHMT is inactive in the absence of a thiol-reducing agent and removal of this protective compound results in a slow irreversible loss of the BHMT catalytic zinc molecule and a concomitant loss of activity. ${ }^{68}$ Thus, the increased induction of BHMT expression observed in the long-term betaine treatment group could constitute an unsuccessful compensatory mechanism designed to ameliorate the effects of diminished BHMT activity. Such an interpretation would be consistent with previous work where BHMT enzyme activity was inhibited by S-( $\Delta$-carboxybutyl)dl-Hcy (D,L-CBHcy) in rats. ${ }^{69}$ In this study, rats responded to $>90 \%$ inhibition of BHMT enzyme activity by inducing expression of the BHMT gene. It is therefore conceivable that coadministration of an antioxidant could facilitate maximal BHMT activity during long-term betaine treatment which would presumably result in greater clinical efficacy. The $\mathrm{HO}$ mouse model of HCU can serve as a useful tool for examining the optimal timing and dosing of betaine treatment with a view towards optimizing clinical outcome.

\section{Acknowledgments}

KNM gratefully acknowledges financial support from the William R Hummel Homocystinuria Research Fund, and wishes to thank Professor Sally Stabler (University of Colorado) and Professor Tim Garrow (University of Illinois) for useful discussions.

\section{Disclosure}

The author reports no conflicts of interest in this work.

\section{References}

1. Finkelstein JD. Methionine metabolism in mammals. J Nutr Biochem. 1990;1:228-237.

2. Maclean KN, Gaustadnes M, Oliveriusova J, et al. High homocysteine and thrombosis without connective tissue disorders are associated with a novel class of cystathionine beta-synthase (CBS) mutations. Hum Mutat. 2002;19(6):641-655.

3. Carson NAJ, Neill DW. Metabolic abnormalities detected in a survey of mentally backward individuals in Northern Ireland. Arch Dis Child. 1962;37:505-513.

4. Gerritsen T, Vaughn JG, Waisman HA. The identification of homocystine in the urine. Biochem Biophys Res Commun. 1962;9: 493-496.

5. Mudd SH, Finkelstein JD, Irreverre F, Laster L. Homocystinuria: An enzymatic defect. Science. 1964;143:1443-1445.

6. Mudd SH, Levy HL, Kraus JP. Disorders of transsulfuration. In: Scriver CR, Beaudet AL, Sly WS, et al, editors. The Metabolic and Molecular Bases of Inherited Disease. 8th ed. New York, NY: McGraw-Hill; 2001:2007-2056.

7. Maclean KN, Jiang H, Greiner LS, Allen RH, Stabler SP. Long-term betaine therapy in a murine model of cystathionine beta-synthase deficient homocystinuria: decreased efficacy over time reveals a significant threshold effect between elevated homocysteine and thrombotic risk. Mol Genet Metab. 2012;105(3):395-403.

8. Barber GW, Spaeth GL. Pyridoxine therapy in homocystinuria. Lancet. $1967 ; 1: 337$ 
9. Kluijtmans LAJ, Boers GHJ, Stevens EMB, et al. Defective cystathionine b-synthase regulation by S-adenosylmethionine in a partially pyridoxine responsive homocystinuria patient. J Clin Invest. 1996;98: 285-289.

10. Janosik M, Kery V, Gaustadnes M, Maclean KN, Kraus JP. Regulation of human cystathionine beta-synthase by S-adenosyl-L-methionine: Evidence for two catalytically active conformations involving an autoinhibitory domain in the C-terminal region. Biochemistry. 2001;40(35): 10625-10633.

11. Mudd SH, Skovby F, Levy HL, et al. The natural history of homocystinuria due to cystathionine b-synthase deficiency. Am J Hum Genet. 1985;37:1-31.

12. Komrower GM, Lambert AM, Cusworth DC, Westall RG. Dietary treatment of homocystinuria. Arch Dis Child. 1966;41(220):666-671.

13. Brenton DP, Cusworth DC, Dent CE, Jones EE. Homocystinuria: Clinical and dietary studies. Q J Med. 1966;35:325-346.

14. Gaull GE, Rassin DK, Sturman JA. Pyridoxine-dependency in homocystinuria. Lancet. 1968;2:1302.

15. Barber GW, Spaeth GL. The successful treatment of homocystinuria with pyridoxine. J Pediatr. 1969;75:463-478.

16. Carson NAJ, Carre IJ. Treatment of homocystinuria with pyridoxine: A preliminary study. Arch Dis Child. 1969;44:387-392.

17. Perry TL, Hansen S, Love DL, Crawford LE, Tischler B. Treatment of homocystinuria with a low-methionine diet, supplemental cystine, and a methyl donor. Lancet. 1968;2:474-478.

18. Komrower GM, Sardharwalla IB. The dietary treatment of homocystinuria. In: Carson NAJ, Raine DN, editors. Inherited Disorders of Sulphur Metabolism. London, UK: Churchill Livingstone, Ltd; 1971:254-263.

19. Wilcken DEL, Dudman NPB, Tyrrell PA. Homocystinuria due to cystathionine b-synthase deficiency - The effects of betaine treatment in pyridoxine-responsive patients. Metabolism. 1985;34:1115-1121.

20. Smolin LA, Benevenga NJ, Berlow S. The use of betaine for the treatment of homocystinuria. J Pediatr. 1981;99:467-472.

21. Wilcken DEL, Wilcken B, Dudman NPB, Tyrrell PA. HomocystinuriaThe effects of betaine in the treatment of patients not responsive to pyridoxine. N Engl J Med. 1983;309:448-453.

22. Wilcken DE, Wilcken B. The natural history of vascular disease in homocystinuria and the effects of treatment. $J$ Inherit Metab Dis. 1997;20(2):295-300.

23. Singh RH, Kruger WD, Wang L, Pasquali M, Elsas LJ 2nd. Cystathionine beta-synthase deficiency: effects of betaine supplementation after methionine restriction in B6-nonresponsive homocystinuria. Genet Med. 2004;6(2):90-95.

24. Carson NAJ, Dent CE, Field CMB, Gaull GE. Homocystinuria: Clinical and pathological review of ten cases. J Pediatr. 1965;66:565-583.

25. Schimke RN, McKusick VA, Huang T, Pollack AD. Homocystinuria. JAMA. 1965;193:711-719.

26. McCully KS. Vascular pathology of homocysteinemia: Implications for the pathogenesis of arteriosclerosis. Am J Pathol. 1969;56: 111-128.

27. Walter JH, Wraith JE, White FJ, Bridge C, Till J. Strategies for the treatment of cystathionine b-synthase deficiency: the experience of the Willink Biochemical Genetics Unit over the past 30 years. Eur $J$ Pediatr. 1998;157(Suppl 2):S71-S76.

28. Yap S, Boers GH, Wilcken B, et al. Vascular outcome in patients with homocystinuria due to cystathionine beta-synthase deficiency treated chronically: a multicenter observational study. Arterioscler Thromb Vasc Biol. 2001;21(12):2080-2085.

29. Skovby F, Gaustadnes M, Mudd SH. A revisit to the natural history of homocystinuria due to cystathionine beta-synthase deficiency. Mol Genet Metab. 2010;99(1):1-3.

30. Abbott MH, Folstein SE, Abbey H, Pyeritz RE. Psychiatric manifestations of homocystinuria due to cystathionine b-synthase deficiency. Am J Med Genet. 1987;26:959-969.

31. Boers G. Homocystinuria. A Risk Factor of Premature Vascular Disease. Riverton, WY: Ferris Publications; 1986.
32. Yap S, Rushe H, Howard PM, Naughten ER. The intellectual abilities of early-treated individuals with pyridoxine-nonresponsive homocystinuria due to cystathionine beta-synthase deficiency. $J$ Inherit Metab Dis. 2001;24(4):437-447.

33. Yap S, Naughten E. Homocystinuria due to cystathionine beta-synthase deficiency in Ireland - 25 years experience of a newborn screened and treated population with reference to clinical outcome and biochemical control. J Inherit Metab Dis. 1998;21:738-747.

34. Mulvihill A, Yap S, O'Keefe M, Howard PM, Naughten ER. Ocular findings among patients with late-diagnosed or poorly controlled homocystinuria compared with a screened, well-controlled population. J AAPOS. 2001;5(5):311-315.

35. Gahl WA, Bernardini I, Chen S, Kurtz D, Horvath K. The effect of oral betaine on vertebral body bone density in pyridoxine-non-responsive homocystinuria. J Inherit Metab Dis. 1988;11:291-298.

36. Gaull GE, Tallan HH. Methionine adenosyltransferase deficiency: New enzymatic defect associated with hypermethioninemia. Science. 1974;186:59-60.

37. Chamberlin ME, Ubagai T, Mudd SH, et al. Methionine adenosyltransferase I/III deficiency: novel mutations and clinical variations. $A m ~ J$ Hum Genet. 2000;66(2):347-355.

38. Mudd SH, Levy HL, Tangerman A, et al. Isolated persistent hypermethioninemia. Am J Hum Genet. 1995;57:882-892.

39. Yaghmai R, Kashani AH, Geraghty MT, et al. Progressive cerebral edema associated with high methionine levels and betaine therapy in a patient with cystathionine beta-synthase (CBS) deficiency. Am J Med Genet. 2002;108(1):57-63.

40. Devlin AM, Hajipour L, Gholkar A, Fernandes H, Ramesh V, Morris AA. Cerebral edema associated with betaine treatment in classical homocystinuria. J Pediatr. 2004;144(4):545-548.

41. Braverman NE, Mudd SH, Barker PB, Pomper MG. Characteristic MR imaging changes in severe hypermethioninemic states. AJNR Am J Neuroradiol. 2005;26(10):2705-2706.

42. Wilcken DE, Wilcken B, Dudman NP, Tyrrell PA. Homocystinuria the effects of betaine in the treatment of patients not responsive to pyridoxine. N Engl J Med. 1983;309(8):448-453.

43. Kishi T, Kawamura I, Harada Y, et al. Effect of betaine on $S$-adenosymethionine levels in the cerebrospinal fluid in a patient with methylenetetrahydrofolate reductase deficiency and peripheral neuropathy. J Inherit Metab Dis. 1994;17:560-565.

44. Berlow S, Bachman RP, Berry GT, et al. Betaine therapy in homocystinemia. Brain Dysfunction. 1989;2:10-24.

45. Alfthan G, Tapani K, Nissinen K, Saarela J, Aro A. The effect of low doses of betaine on plasma homocysteine in healthy volunteers. $\mathrm{Br} J$ Nutr. 2004;92(4):665-669.

46. Olthof MR, Verhoef P. Effects of betaine intake on plasma homocysteine concentrations and consequences for health. Curr Drug Metab. 2005;6(1):15-22.

47. Schwab U, Torronen A, Meririnne E, et al. Orally administered betaine has an acute and dose-dependent effect on serum betaine and plasma homocysteine concentrations in healthy humans. J Nutr. 2006;136(1):34-38.

48. Atkinson W, Elmslie J, Lever M, Chambers ST, George PM. Dietary and supplementary betaine: acute effects on plasma betaine and homocysteine concentrations under standard and postmethionine load conditions in healthy male subjects. Am J Clin Nutr. 2008;87(3):577-585.

49. Matthews A, Johnson TN, Rostami-Hodjegan A, et al. An indirect response model of homocysteine suppression by betaine: optimising the dosage regimen of betaine in homocystinuria. Br J Clin Pharmacol. 2002;54(2):140-146.

50. Schwahn BC, Hafner D, Hohlfeld T, Balkenhol N, Laryea MD, Wendel U. Pharmacokinetics of oral betaine in healthy subjects and patients with homocystinuria. Br J Clin Pharmacol. 2003;55(1):6-13.

51. Sakamoto A, Sakura N. Limited effectiveness of betaine therapy for cystathionine beta synthase deficiency. Pediatr Int. 2003;45(3):333-338.

52. Lawson-Yuen A, Levy HL. The use of betaine in the treatment of elevated homocysteine. Mol Genet Metab. 2006;88(3):201-207. 
53. Yokoi K, Ito T, Ohkubo Y, et al. Long follow up of betaine therapy in two Japanese siblings with cystathionine beta-synthase deficiency. Pediatr Int. 2008;50(5):694-695.

54. Watanabe M, Osada J, Aratani Y, et al. Mice deficient in cystathionine beta-synthase: animal models for mild and severe homocyst(e)inemia. Proc Natl Acad Sci U S A. 1995;92(5):1585-1589.

55. Maclean KN, Sikora J, Kozich V, et al. Cystathionine beta-synthase null homocystinuric mice fail to exhibit altered hemostasis or lowering of plasma homocysteine in response to betaine treatment. Mol Genet Metab. 2010;101(2-3):163-171.

56. Maclean KN, Sikora J, Kozich V, et al. A novel transgenic mouse model of CBS-deficient homocystinuria does not incur hepatic steatosis or fibrosis and exhibits a hypercoagulative phenotype that is ameliorated by betaine treatment. Mol Genet Metab. 2010;101(2-3): $153-162$.

57. Keating AK, Freehauf C, Jiang H, et al. Constitutive induction of proinflammatory and chemotactic cytokines in cystathionine beta-synthase deficient homocystinuria. Mol Genet Metab. 2011;103(4):330-337.

58. Mundy GR. Osteoporosis and inflammation. Nutr Rev. 2007;65(12 Pt 2): S147-S151.

59. Gupta S, Kuhnisch J, Mustafa A, et al. Mouse models of cystathionine beta-synthase deficiency reveal significant threshold effects of hyperhomocysteinemia. FASEB J. 2009;23(3):883-893.

60. Jiang H, Stabler SP, Allen RH, Maclean KN. Altered expression of apoA-I, apoA-IV and PON-1 activity in CBS deficient homocystinuria in the presence and absence of treatment: Possible implications for cardiovascular outcomes. Mol Genet Metab. 2012;107(1-2): $55-65$.
61. Saito H, Lund-Katz S, Phillips MC. Contributions of domain structure and lipid interaction to the functionality of exchangeable human apolipoproteins. Prog Lipid Res. 2004;43(4):350-380.

62. Wong WM, Gerry AB, Putt W, et al. Common variants of apolipoprotein A-IV differ in their ability to inhibit low density lipoprotein oxidation. Atherosclerosis. 2007;192(2):266-274.

63. Hoffer LJ. Homocysteine remethylation and trans-sulfuration. Metabolism. 2004;53(11):1480-1483.

64. Blom HJ, Boers GHJ, Trijbels JMF, van Roessel JJM, Tangerman A. Cystathionine-synthase-deficient patients do not use the transamination pathway of methionine to reduce hypermethioninemia and homocystinemia. Metabolism. 1989;38:577-582.

65. Duerre JA, Miller CH, Reams GG. Metabolism of $S$-adenosyl-Lhomocysteine in vivo by the rat. J Biol Chem. 1969;244:107-111.

66. Skiba WE, Taylor MP, Wells MS, Mangum JH, Awad WM Jr. Human hepatic methionine biosynthesis. Purification and characterization of betaine-homocysteine $S$-methyltransferase. J Biol Chem. 1982;257:14944-14948.

67. Miller CM, Szegedi SS, Garrow TA. Conformation-dependent inactivation of human betaine-homocysteine S-methyltransferase by hydrogen peroxide in vitro. Biochem J. 2005;392(Pt 3):443-448.

68. Castro C, Millian NS, Garrow TA. Liver betaine-homocysteine S-methyltransferase activity undergoes a redox switch at the active site zinc. Arch Biochem Biophys. 2008;472(1):26-33.

69. Strakova J, Gupta S, Kruger WD, et al. Inhibition of betaine-homocysteine $\mathrm{S}$-methyltransferase in rats causes hyperhomocysteinemia and reduces liver cystathionine beta-synthase activity and methylation capacity. Nutr Res. 2011;31(7):563-571
Orphan Drugs: Research and Reviews

\section{Publish your work in this journal}

Orphan Drugs: Research and Reviews is an international, peer-reviewed, open access journal publishing original research, reports, reviews and commentaries on all areas of the design and development of orphan drugs for the treatment of rare diseases through to clinical applications. Clinical outcomes, patient safety, and programs for the development and

\section{Dovepress}

effective, safe, and sustained use of medicines will be a feature of the journal. The manuscript management system is completely online and includes a very quick and fair peer-review system, which is all easy to use. Visit http://www.dovepress.com/testimonials.php to read real quotes from published authors. 